\title{
SOCIALIZAÇÃO ORGANIZACIONAL DE PESSOAS COM DEFICIÊNCIA
}

\author{
ORGANIZATIONAL SOCIALIZATION OF PEOPLE WITH DISABILITY \\ SOCIALIZACIÓN ORGANIZACIONAL DE PERSONAS CON DEFICIENCIAS
}

\section{RESUMO}

O objetivo da pesquisa foi identificar as principais características do processo de socialização das pessoas com deficiência (PCDs) nas organizações. Consideraram-se três dimensões do processo de socialização: biográfica, relacional e organizacional. Identificou-se ações de busca de domínio do trabalho, ações de integração ao grupo de trabalho e ações de conhecimento dos valores da organização realizadas pelas próprias PCDs. As organizações não tinham táticas de socialização sistematizadas. Ficou evidenciada a associação positiva entre táticas de socialização individualizadas e percepção de ações de adequação das práticas e condições de trabalho.

PALAVRAS-CHAVE Socialização organizacional, pessoas com deficiência, diversidade, trabalho, gestão da diversidade.

\author{
Maria Nivalda de Carvalho-Freitas nivalda@ufsj.edu.br \\ Professora do Departamento de Psicologia, Universidade Federal de São João del-Rei - São João del-Rei - MG, Brasil \\ Isadora D’Ávila Toledo isadoradtoledo@gmail.com \\ Mestranda em Psicologia pelo Programa de Mestrado, Universidade Federal de São João del-Rei - São João del-Rei - MG, Brasil
}

Maristela Ferro Nepomuceno maristelapsicologia@yahoo.com.br
Psicóloga pelo Departamento de Psicologia, Universidade Federal de São João del-Rei - São João del-Rei - MG, Brasil

Janayna de Cássia Coelho Suzano janaynasuzano@hotmail.com

Mestranda em Psicologia pelo Programa de Mestrado, Universidade Federal de São João del-Rei - São João del-Rei - MG, Brasil

Luciana Alves Drumond Almeida luciana.drumond@yahoo.com.br

Mestranda em Sociologia, Programa de Pós-Graduação em Sociologia, Universidade Federal de Minas Gerais - Belo Horizonte - MG, Brasil

Recebido em 12.11.2009. Aprovado em 09.06.2010

Avaliado pelo sistema double blind review

Editor Científico: Alexandre de Pádua Carrieri

\begin{abstract}
The objective was to identify the main characteristics of the socialization process of people with disability (PWD) within organizations, in its biographical, relational and organizational dimensions. The results of interviews with 9 PWD from 3 organizations in Minas Gerais state and the questionnaires applied to 33 PWD in the Belo Horizonte Metropolitan Region were analyzed. What was identified was the predominance of actions by which the disabled themselves seek to master work, integrate into the group and acquire knowledge of organizational values, although they use no systematic socialization tactics. Evidence was gathered of a positive association between individual socialization tactics and the perception of actions for adjusting working practices and conditions.
\end{abstract}

KEYWORDS Organizational socialization, people with disability, diversity, job, management of diversity.

RESUMEN El objetivo fue identificar las principales características del proceso de socialización de las personas con deficiencias (PCD) en las organizaciones, en las dimensiones biográfica, relacional y organizacional. Se analizaron resultados de entrevistas con nueve PCD de tres organizaciones del interior del estado de Minas Gerais y de cuestionarios aplicados a 33 PCD de la Región Metropolitana de la ciudad de Belo Horizonte. Se identificó el predominio de acciones de busca de dominio del trabajo, de integración al grupo y de conocimiento de los valores organizacionales, realizadas por las propias $P C D$, sin tácticas sistematizadas de socialización. Se evidenció asociación positiva entre tácticas de socialización individualizadas y percepción de acciones de adecuación de las prácticas y condiciones de trabajo.

PALABRAS CLAVE Socialización organizacional, personas con deficiencia, diversidad, trabajo, gestión de la diversidad. 


\section{INTRODUÇÃO}

No Brasil, segundo o censo realizado em 2000 pelo Instituto Brasileiro de Geografia e Estatística (IBGE), existem 24,5 milhões de pessoas portadoras de algum tipo de deficiência, o que representa $14,5 \%$ da população brasileira. Com relação à população mundial, cerca de $10 \%$ possui algum tipo de deficiência, o que significa em torno de 650 milhões de pessoas, $72 \%$ das quais estão em idade produtiva (ORGANIZAÇÃO INTERNACIONAL DO TRABALHO, 2009). Dessas pessoas, pouco menos da metade nasce com deficiência, enquanto a maioria se torna portadora de algum tipo de deficiência depois dos 16 anos, principalmente durante a vida laboral (CONFERENCIA INTERNACIONAL DEL TRABAJO, 2007).

Para a Organização Internacional do Trabalho, pessoa com deficiência

[...] é indivíduo cujas perspectivas de obter emprego apropriado, reassumi-lo, mantê-lo e nele progredir são substancialmente reduzidas em virtude de deficiência física, auditiva, visual, mental ou múltipla devidamente reconhecida, agravadas pelas dificuldades locais de inclusão no mundo do trabalho (SECRETARIA INTERNACIONAL DO TRABALHO, 2006, p. 5).

Em função da Lei de Cotas (Decreto n. 3.298/99), parte das políticas afirmativas brasileiras, as organizações com mais de 100 funcionários, têm uma nova ordenação compulsória: admitir pessoas com deficiência (PCDs). Essa nova exigência traz para o cenário das organizações a necessidade de gerir o trabalho dessas pessoas, o que, por definição, é uma atividade complexa, pois são diversos os tipos de deficiência, em diversas intensidades, que podem ter impacto diferenciado sobre as necessidades de adequação das condições e práticas de trabalho.

As pesquisas indicam que há falta de preparo social, assim como inúmeras barreiras funcionais e arquitetônicas. Contratar uma pessoa com deficiência apenas para cumprir a Lei, sem remover barreiras que facilitem o acesso dessa pessoa, contribui para aumentar o preconceito de que ela não possui competência laboral (TANAKA e MANZINI, 2005). O preconceito em torno da capacidade contributiva no contexto empresarial é um dos maiores obstáculos para a inclusão social (OMOTE, 1987; GLAT, 1995; CROCHÍK, 1996; MARQUES, 2001; POPOVICH e outros, 2003; QUINTÃO, 2005; dentre outros). Os preconceitos estão fundados em crenças generalizadas sobre características pessoais (atributos) de grupos minoritários, as quais são consideradas como tipicamente negativas (GOFFMAN, 1982).

$\mathrm{Na}$ atualidade, existem várias pesquisas que identificam as dificuldades das pessoas com deficiência (PCDs) para se inserirem no mercado de trabalho (NERI e outros, 2003; HEINSKI e BIGNET, 2002; BATISTA, 2004; GOSS, GOSS e ADAM-SMITH, 2000; CARVALHO-FREITAS, MARQUES e SCHERER, 2005, dentre outras), e um número crescente de pesquisas que se ocupam com a gestão do trabalho de PCDs já inseridas na organização (LEWIS e ALLEE, 1992; STONE e COLELLA, 1996; BAHIA, 2006; CARVALHOFREITAS E MARQUES, 2008; CARVALHO-FREITAS, 2009, dentre outras).

Especialmente sobre o processo de socialização organizacional das PCDs, muito poucas investigações foram produzidas (COLELLA, 1996). Entende-se por socialização organizacional o "processo de integração do indivíduo com a organização no exercício de determinado cargo" (BORGES e ALBUQUERQUE, 2004, p. 333).

Considerando o desconhecimento em relação às possibilidades de trabalho das PCDs e as dificuldades no seu processo de inserção, o objetivo da presente pesquisa foi verificar se existem relações entre as expectativas profissionais e estratégias de busca de informações das PCDs (dimensão biográfica); a percepção dessas pessoas em relação a como são vistas por chefias e colegas de trabalho (dimensão social); e as práticas organizacionais adotadas pelas organizações para a integração de funcionários portadores de deficiência (dimensão organizacional). A intenção foi identificar as principais características do processo de socialização das PCDs. O foco da pesquisa foram pessoas com deficiência física, auditiva e visual sem comprometimento intelectual.

\section{REFERENCIAL TEÓRICO}

Numa visão ampliada, entende-se por socialização organizacional o processo de aprendizagem de valores, crenças e formas de concepção do mundo próprio de uma determinada cultura organizacional. Esse processo pode ser identificado à aquisição de um ethos organizacional, tácito, não necessariamente expresso em palavras, que oferece ao agente as condições necessárias para discriminar como deve se portar e atuar, qual o grau de tolerância da organização para com as diferenças e divergências, que expectativas profissionais pode alimentar, que questões podem ser explicitadas, quando, como e a quem se dirigir, o que deve ser valorizado e o que deve ser esqueci- 
do ou, pelo menos, não problematizado explicitamente (CARVALHO-FREITAS, 2002).

Conforme Borges e Albuquerque (2004), o primeiro ano de trabalho é o período crítico no processo de socialização das pessoas.

Utilizando-se Dubar (1997) como referência de análise, serão consideradas três dimensões específicas e articuláveis entre si para se compreender o processo de socialização organizacional das PCDs: a dimensão biográfica; a dimensão relacional e a dimensão organizacional.

\section{Dimensão biográfica}

Essa dimensão diz respeito à história do indivíduo em processo de socialização e suas expectativas de inserção no mercado de trabalho e construção de uma identidade profissional futura. Nessa dimensão de análise, o foco é o indivíduo: são consideradas a percepção de sua trajetória profissional, suas expectativas de inserção no mercado de trabalho e suas projeções de futuro profissional. Além disso, consideram-se as estratégias de busca de informações para a redução de incertezas no processo de socialização (BARKER, 1995; MILLER e JABLIN, 1991; SAKS e ASHFORTH, 1997).

Sobre a busca de informações, os estudos de Ostroff e Kozlowski (1992) indicam quatro domínios que abrangem o processo de socialização: tarefas do emprego, papéis de trabalho, processos de grupo e atributos organizacionais. Esses domínios são considerados como informações de conteúdos diferentes: os relacionados ao trabalho propriamente dito (tarefas do emprego); à aprendizagem do papel social do cargo dentro da organização (papéis de trabalho); às informações sobre o grupo de trabalho (processos de grupo); e sobre os valores organizacionais (atributos organizacionais).

É importante considerar quais domínios de informações são privilegiados pelas PCDs no processo de socialização organizacional, as estratégias que utilizam para ter acesso a essas informações e as principais fontes de informação.

$\mathrm{Na}$ presente pesquisa serão utilizadas as táticas que os indivíduos empregam tendo em vista sua socialização e que foram identificadas por Griffin, Colella e Goparaju (2000) a partir de uma extensa revisão de literatura sobre a socialização. As principais táticas são: busca de informação e feedback; construção de relacionamentos, relacionamento com um tutor informal, negociação de mudança nas atividades do posto de trabalho, autogerenciamento das informações, envolvimento em atividades relacionados ao trabalho, autoavaliação, observação, e estratégias de desenvolvimento de carreira.

\section{Dimensão relacional}

A dimensão relacional é como o sujeito é identificado pelos outros. Envolve um ato de atribuição da identidade pela organização e pelos agentes diretamente em interação com os indivíduos em processo de socialização. Não pode ser analisado fora dos sistemas de ação nos quais os indivíduos estão implicados (DUBAR, 1997). No que se refere a esta pesquisa, é necessário considerar a percepção das PCDs em relação à forma como elas são vistas na organização.

Segundo Marques (1999), a minimização das barreiras sociais propicia às PCDs maior integração física, bem como a dissolução do preconceito e da discriminação no contexto social. Coerente com essa perspectiva, surge o conceito de acessibilidade, que envolve a eliminação das barreiras físicas, de comunicação e atitudinais. As primeiras dizem respeito às barreiras arquitetônicas e de mobiliários, que dificultam a mobilidade das PCDs. As barreiras de comunicação são aquelas que impedem uma plena comunicação interpessoal, escrita e virtual. Enquanto as barreiras atitudinais se referem aos valores e concepções sobre a deficiência e associam-se à discriminação, ao preconceito, aos estigmas e estereótipos (VIVARTA, 2003).

Admitindo que as formas de ver a deficiência estejam ancoradas em concepções de homem e mundo, conscientes ou não, buscaram-se na literatura referências que pudessem ajudar a identificar maneiras de ver a deficiência que se mantiveram ao longo da história. Assim, será utilizada na pesquisa a tipologia construída por CarvalhoFreitas (2007) que identificou tipos de concepções de deficiência a partir de uma extensa revisão da literatura sobre a deficiência.

Essa tipologia desenvolvida para identificar as formas como as pessoas vêem a deficiência será utilizada para verificar como as PCDs, em processo de socialização, acreditam ser vistas pelos colegas de trabalho e chefias.

Três dimensões ou tipos de concepções de deficiência identificadas por Carvalho-Freitas (2007) serão objeto de análise das PCDs em processo de socialização:

1. A normalidade como matriz de interpretação: as pessoas que compartilham esta concepção têm na norma seu padrão de avaliação, sendo a deficiência considerada um "desvio" ou "doença" que necessita de cuidados especiais dos profissionais da saúde. Para as pessoas que possuem essa visão da deficiência, a possibilidade de inserção das PCDs se dá mediante a reabilitação e a adequação delas ao sistema social. Geralmente, as pessoas que compartilham esta concepção consideram que as PCDs assumem atitudes inadequadas no trabalho, provocando situações embaraçosas, são mais propensas 
a acidentes, têm problemas de relacionamento e devem ser alocadas em setores específicos da empresa.

2. A inclusão como matriz de interpretação: esta concepção é compartilhada pelas pessoas que deslocam sua percepção da deficiência de um problema individual para um problema social. O pressuposto compartilhado pelas pessoas que possuem esta visão da deficiência é de que a sociedade tem que se adaptar para incluir a todos e a que inclusão das PCDs deve ser feita a partir de suas potencialidades.

3. Percepção de desempenho: como característica geral, este fator focaliza a percepção das pessoas em relação ao desempenho, produtividade e qualidade de trabalho das PCDs e suas implicações para a competitividade da empresa.

As demais concepções de deficiência identificadas por Carvalho-Freitas (2007) não foram utilizadas na presente pesquisa por se considerar que diziam respeito à questões que as PCDs teriam mais dificuldades em perceber em suas relações com colegas de trabalho e chefias.

\section{Dimensão organizacional}

Essa dimensão diz respeito à organização e suas práticas de socialização para viabilizar o processo de inserção de PCDs. Por práticas organizacionais entende-se o conjunto de ações desenvolvidas pela organização que possam facilitar o processo de socialização das PCDs. Serão consideradas duas dimensões de análise: táticas organizacionais e condições de trabalho.

\section{Táticas organizacionais}

"Conjunto de ações que têm entre os seus objetivos tornar o indivíduo um membro efetivo da organização" (BORGES e ALBUQUERQUE, 2004, p. 335).

Segundo Van Maanen e Schein (1979), as táticas organizacionais nem sempre são planejadas e implicam um número infinito de ações que podem ser realizadas e que contribuem para a integração do indivíduo na organização. Alguns dos muitos exemplos de táticas organizacionais são: treinamento de integração dos novos funcionários, tutoria, treinamento técnico na função, atividades de grupo etc.

Van Maanen e Schein (1979) desenvolveram, então, um modelo de análise das táticas organizacionais de socialização que se caracterizam pelos meios ou recursos utilizados, independentemente da ação propriamente dita. São elas:

- Coletiva versus individual: tática que envolve experiências coletivas ou individuais.
- Formal versus informal: envolve tratamento formalizado dos novos funcionários de forma separada dos demais trabalhadores da organização ou ocorre no cotidiano de trabalho.

- Sequencial versus randômica: é uma tática desenvolvida em graus dirigidos ao papel que o novo funcionário irá desempenhar ou é uma atividade aleatória.

- Fixa versus variável: existe um cronograma para o processo de socialização ou esse processo não obedece a uma cronologia.

- Serial versus disjuntiva: a tática pressupõe procedimentos de acompanhamento dos antigos funcionários (serial) ou não.

- Investimento versus desinvestimento: tática que considera a identidade, as habilidades e aptidões do iniciante ou que provoca a ruptura com a identidade anterior.

Jones (1986) aperfeiçoando o modelo de Van Maanen e Schein (1979), organizou as dimensões bipolares apresentadas em táticas institucionalizadas (coletiva, formal, fixo, sequencial, serial e de investimento) e táticas individualizadas (individual, informal, variável, randômica, disjuntiva e de desinvestimento). As táticas definidas por Van Maanen e Schein (1979) foram objetos de análise na presente pesquisa.

\section{Condições de trabalho}

Segundo Freund (2001), as questões relacionadas à deficiência precisam ser situadas em um tempo e em um espaço determinados. Além disso, afirma que pouca atenção tem sido dada à organização social do espaço como um elemento que produz tanto a saúde como a doença. Para ele, a organização social do espaço não é apenas um lugar em que as interações sociais ocorrem; ela estrutura tais interações. Afirma que o espaço sociomaterial não é um objeto inerte, mas expressa e estrutura a vida social. O espaço é importante porque oferece possibilidades e constrangimentos para os corpos. Nesse sentido, o espaço social não é neutro, mas político nas prioridades que concede a determinadas maneiras de organização das interações.

Kitchin (1998) também destaca o papel do espaço na reprodução e manutenção do processo de exclusão. Para ele, não se pode compreender como as pessoas se tornam marginalizadas e excluídas da sociedade sem que se faça uma apreciação do processo socioespacial, que reproduz as relações sociais.

Essa pesquisa compartilha a perspectiva de que a organização social do espaço é uma categoria importante para os estudos sobre a deficiência, pois legitima as diferenças e 
propicia as distinções sociais (cada um em seu lugar). No entanto, em vez de ser utilizada a terminologia "espaço", será utilizada, por sua maior especificidade, a terminologia "ações de adequação das condições e práticas de trabalho", definida como sendo os elementos cuja presença ou ausência modificam a relação de forças entre pessoas com e sem deficiência nas organizações. Foi, então, utilizado o Inventário de Ações de Adequação das Condições e Práticas de Trabalho (IACPT), que, em sua versão final (CARVALHO-FREITAS, 2009), contempla três fatores, que serão utilizados na presente pesquisa:

Sensibilização: este fator focaliza a percepção das pessoas em relação às ações da empresa no sentido de sensibilizar as chefias e funcionários para a inserção de PCDs e fornecer informações sobre saúde e segurança no trabalho às PCDs contratadas.

Adaptações: este fator focaliza a percepção das pessoas em relações às adaptações nas condições e instrumentos de trabalho realizadas pela empresa para facilitar a inserção de PCDs.

Práticas de RH: este fator focaliza a percepção das pessoas em relação à adequação das práticas de seleção, treinamento, promoção e transferência realizadas pela empresa com vistas a inserir as PCDs.

\section{MÉTODO UTILIZADO}

A pesquisa se desenvolveu em duas etapas:

Primeira etapa: Foi realizado um estudo exploratório com amostra de conveniência, devido à possibilidade de acesso às PCDs. Participaram da pesquisa nove PCDs, oito em seu primeiro ano de trabalho, oriundas de três organizações localizadas em Minas Gerais: uma instituição pública e duas instituições privadas.

O método de pesquisa adotado nesta etapa foi qualitativo em sua forma de obtenção e análise dos dados. Foram realizadas entrevistas com os responsáveis pela área de Recursos Humanos e com as chefias imediatas das PCDs visando caracterizar as táticas organizacionais desenvolvidas com vistas a promover a integração dessas pessoas. Foram entrevistadas as PCDs visando caracterizar as trajetórias profissionais e expectativas de carreira, além das táticas que os indivíduos empregam tendo em vista sua socialização.

A análise das entrevistas foi realizada tendo como referência o conteúdo delas, isto é, a posição das pessoas quanto aos aspectos pesquisados (BARDIN, 1994). Para essa análise, são sugeridas algumas etapas, como: realização de "leitura flutuante" das questões; agrupamento e classificação das questões segundo critérios definidos a partir da leitura realizada - "exploração exaustiva"; e identificação de relações realizadas pelos respondentes (BARDIN, 1994, p. 60).

Segunda etapa: Após a conclusão da primeira etapa exploratória, foi realizado um estudo com 33 PCDs que trabalhavam em instituições financeiras privadas na Região Metropolitana de Belo Horizonte. A amostra foi definida por critérios de conveniência, contemplando instituições que tinham PCDs e que autorizaram a realização da pesquisa. O objetivo foi verificar, em uma amostra maior, se havia relações entre as táticas de socialização privilegiadas pelas PCDs em seus processos de socialização; e a percepção que elas tinham das adequações das condições e práticas de trabalho realizadas nas organizações em que trabalhavam. Foram aplicados: o Inventário de Táticas Individuais Utilizadas no Processo de Socialização, construído a partir do referencial de Ostroff e Koslowski (1992) e Griffin, Colella e Goparaju (2000), e o Inventário de Condições e Práticas de Trabalho para a Inserção de Pessoas com Deficiência (CARVALHO-FREITAS, 2009), ambos utilizando a Escala Likert de 1 a 6 (de Discordo totalmente a Concordo totalmente).

A apresentação e análise dos dados envolveram a utilização de técnicas estatísticas, a saber: estatística descritiva e análise da correlação de Pearson visando verificar a ocorrência de correlações (direção e intensidade das associações) entre as táticas adotadas e a percepção de adequação das condições e práticas de trabalho.

\section{APRESENTAÇÃO E DISCUSSÃO DOS RESULTADOS}

Serão apresentados, a seguir, os resultados das duas etapas da pesquisa realizada.

\section{Primeira etapa da pesquisa}

Nesta etapa serão apresentados os resultados das análises das entrevistas realizadas com os gestores das PCDs e os das entrevistas realizadas com as próprias PCDs.

\section{Gestores de pessoas com deficiência}

$\mathrm{Na}$ primeira etapa da pesquisa, foi realizada a análise qualitativa das entrevistas de gerentes e profissionais de Recursos Humanos das três organizações mineiras que tinham PCDs em seu primeiro ano de trabalho e que concordaram em participar da pesquisa. Foram entrevistados oito gestores da instituição pública e três de uma das organizações privada. Os gestores da outra organização não participaram da pesquisa, em função de dificuldades 
internas. Todos os gestores entrevistados trabalhavam diretamente com as PCDs que fizeram parte da pesquisa.

Pela análise dos dados constatou-se que as duas organizações apresentam características similares quanto às ações e táticas de socialização, não tendo sido identificadas ações diferenciadas entre a instituição pública e a organização privada participantes da pesquisa. Com relação às ações de integração das PCDs contratadas, observou-se pela fala dos gestores, que poucas ações são realizadas pelo setor de Recursos Humanos das empresas para integrar as PCDs, e o próprio setor não promove ações sistematizadas em prol da integração dessas pessoas ao trabalho.

A maioria dos gestores justifica a falta da promoção de ações integradoras e a falta de acompanhamento do trabalho das PCDs e das suas necessidades por considerarem a pessoa com deficiência igual aos outros funcionários, negando, assim, a deficiência e, consequentemente, a necessidade de adaptação das condições e dos instrumentos de trabalho: "Tratamento normal, igual ao de todo mundo" ou "A gente age naturalmente como se ele fosse um servidor como outro". Outra justificativa recorrente foi a facilidade que a pessoa com deficiência possui de se integrar ao grupo e, também, o fato de o ambiente de trabalho ser harmônico e tranquilo: "Nós não fizemos muito. Ela por si própria é uma pessoa descontraída e o ambiente de trabalho não é rígido. Ela se socializa"; "A empresa não se adaptou para receber a pessoa, ela que teve que se adaptar à empresa". Essas ações dos gestores são referendadas pela percepção das PCDs e se confirmam em duas situações relatadas pelos entrevistados: duas PCDs que tinham mobilidade reduzida nas mãos foram destinadas a funções que requeriam destreza manual, e as organizações não fizeram nenhuma adequação que viabilizasse o trabalho delas. Essa ausência de adaptação das condições e instrumentos de trabalho segundo as necessidades das PCDs reafirma os resultados de outras pesquisas, como, por exemplo, a de Tanaka e Manzini (2005), e pode contribuir para aumentar o preconceito de que as PCDs não possuem competência laboral.

Nos setores onde o clima organizacional foi descrito como tranquilo e os gestores e colegas de trabalho se mostraram receptivos e abertos às diferenças, os gerentes relataram desenvolver um processo informal de integração das PCDs. "Aqui a gente é meio como uma família. A PCD não tem só uma função. Se a gente precisa dele para alguma atividade a gente dá abertura, por acreditar na capacidade dele" ou "Ela é muito observadora, atenta no trabalho (...). O ambiente é bem leve". Essas constatações indicam que o clima favorável do setor é considerado como o elemento que propicia a integração nas organi- zações pesquisadas. Embora essa tática possa favorecer a cooperação dentro do grupo, a disseminação dos valores organizacionais, mediante uma abordagem coletiva e formal por parte da organização, fica prejudicada. A PCD terá que aprender, por ensaio e erro, o que é valorizado na organização, podendo apresentar comportamentos considerados inadequados pela ausência de informações sobre a cultura da organização. Esses resultados mostram uma realidade que difere da de estudos anteriores que enfatizam a importância de uma cultura pautada na diversidade e na responsabilidade social (RIBEIRO, M. A. e RIBEIRO, F, 2008) e dos estudos que indicam o impacto de processos de sensibilização e adequação das condições e práticas de trabalho (CARVALHO-FREITAS, 2009) na inserção de PCDs nas organizações de trabalho.

Ao serem questionados sobre a forma como desenvolvem as ações de integração, os gestores foram enfáticos ao responderem que as experiências são individuais, ou seja, cada funcionário do setor se integra por meio de ações particulares: "São ações mais individuais, de acordo com quem está lidando com a situação". Geralmente, são ações aleatórias e sem nenhum planejamento sistematizado para o processo: "É aleatória, na medida em que acontecem as situações. Não tem cronograma". Essa ausência de informações sistematizadas sobre o trabalho, sobre as atividades de desenvolvimento vindouras, sobre as perspectivas que essas pessoas terão dentro da organização pode dificultar as PCDs no discernimento quanto ao melhor caminho a tomar para favorecer o seu próprio crescimento dentro da organização, além de poder vir a criar problemas relacionados à sua satisfação e comprometimento, conforme já indicado em outras pesquisas sobre socialização (HITT, MILLER e COLELLA, 2007).

\section{Pessoas com deficiência entrevistadas}

As PCDs entrevistadas possuíam em sua maioria (56\%) idade entre 20 e 24 anos, sendo que as demais se dividiam em: $22 \%$ entre 30 e 34 anos; e $22 \%$ entre 45 e 49 anos. $67 \%$ são pessoas do sexo masculino. $56 \%$ pertencem à instituição pública. $89 \%$ são de pessoas com deficiência física e $11 \%$ de pessoas com deficiência auditiva. $67 \%$ da amostra são compostos por pessoas solteiras. $56 \%$ possuem ensino médio completo; $22 \%$ possuem ensino superior incompleto; $11 \%$, ensino médio incompleto; e $11 \%$, pós-graduação em curso. Todos se declaram de cor branca.

Considerando os aspectos funcionais da amostra pesquisada, observa-se que a maioria (56\%) já havia trabalhado no mercado formal anteriormente; $22 \%$ haviam trabalhado no mercado informal; e $22 \%$ estão no primeiro emprego. Em relação ao atual emprego, observa-se que a 
maioria o conseguiu por meio do Sistema de Cotas (89\%), com média de seis meses de trabalho. Ocupa em sua maior parte cargo de nível administrativo (89\%); apenas 11\% ocupam cargo operacional; e possui nível salarial equivalente a dois salários mínimos (67\%).

Retomando a dimensão biográfica, por meio da análise das questões relativas à trajetória profissional, verifica-se, primeiramente, a importância do apoio familiar para essas pessoas. Além disso, as PCDs relatam um movimento de busca de empregos e qualificações anteriores. No entanto, elas falam de experiências de frustração diante dessas tentativas, por exemplo: "Eu tentei emprego em um banco, em um comércio e em consultório de dentista e não fui selecionada, mas não disseram o porquê". Esses resultados encontram apoio em estudos anteriores, como os de Carvalho-Freitas, Marques e Scherer (2005) e Nohara, Acevedo e Fiammetti (2008). Muitos respondentes relataram também que os trabalhos anteriores não exigiam qualificação profissional: "Eu trabalhava com negócio de panfletagem, carregava peso, já tava ficando com problema de coluna".

Além disso, constatam-se relatos de dificuldades durante o processo de escolarização, por exemplo: "Até o terceiro ano eu era muito sozinha porque quase ninguém queria fazer trabalho comigo"; "Na época da escola fui muito discriminado, os caras brincavam comigo e eu não gostava".

Em relação ao primeiro momento de inserção no trabalho, notam-se inicialmente insegurança, ansiedade e medo de não conseguir executar as tarefas solicitadas: "Fiquei com muito medo de não dar conta do serviço, por não ter experiência", "O primeiro dia de trabalho foi de muita ansiedade e nervosismo".

Em relação às táticas de socialização adotadas pelas PCDs, especialmente sobre o processo de busca de informações, verifica-se que: em relação ao domínio do trabalho propriamente dito, todas das PCDs buscam ativamente informações sobre como fazer o trabalho, principalmente com colegas e superiores. Em relação à aprendizagem do papel social do cargo dentro da organização, a maioria das pessoas busca informações sobre as expectativas da organização em relação ao trabalho delas, principalmente com seus chefes imediatos. Sobre as informações sobre o grupo de trabalho, quase a totalidade das pessoas tem observado e conversado com as pessoas buscando conhecer e se integrar ao grupo de trabalho. Sobre os valores e atributos organizacionais, quase todas as pessoas têm buscado informações sobre a organização em que trabalham, principalmente com os colegas de trabalho.

Em relação às táticas que as PCDs, em sua maioria, têm utilizado para se integrar nas organizações, pode-se constatar que: buscam informações; procuram saber como o trabalho delas é avaliado; buscam manter um bom relacionamento com as pessoas; procuram ajuda junto aos colegas de trabalho e junto à chefia imediata; buscam estar atentas às informações divulgadas na organização; procuram se envolver nas atividades relacionadas ao seu trabalho e observar seu ambiente de trabalho; buscam definir formas de se desenvolver e fazer carreira na organização; e fazem regularmente autoavaliação de seu desempenho. No entanto, apenas um terço das PCDs entrevistadas negocia mudanças nas atividades de trabalho quando têm dificuldades para realizá-las. Essa atitude de não conversar nem negociar modificações no trabalho pode ser um fator propiciador de avaliações negativas sobre o desempenho das PCDs. Embora essa dificuldade possa ser atribuída às próprias PCDs, alegando-se que elas têm receio de ser mal avaliadas, as organizações favorecem esse comportamento ao incentivar táticas de socialização individualizadas, não explicitando formal e coletivamente como as organizações veem essas iniciativas de solicitação de mudança.

Em relação à dimensão relacional, pode-se constatar que as PCDs acreditam que seus colegas de trabalho e chefias consideram a deficiência como um desvio da normalidade, principalmente no que diz respeito à alocação delas em setores específicos da organização, por exemplo: "O primeiro erro do pessoal do serviço foi a falta de conhecimento; eles não olharam minhas potencialidades e sim a função e minha deficiência". Em relação ao desempenho, 60\% das PCDs acreditam que seus colegas e chefias pensam que elas têm desempenho similar ao das demais pessoas e $40 \%$ têm dúvida sobre essa questão. É importante ressaltar que a boa receptividade por parte dos colegas de trabalho foi evidenciada nos discursos: "O povo me recebeu superbem. Aos poucos fui interagindo com todos". Além disso, pode-se verificar, de uma forma geral, que há um bom relacionamento com os colegas de trabalho, com a chefia e com os grupos de que participam. Esses resultados apoiam estudos anteriores, como o de Nohara, Acevedo e Fiammetti (2008), mas são contrários aos resultados de pesquisas que investigam a violência moral sofrida pelas PCDs (SIQUEIRA e OLIVEIRA-SIMÕES, 2008).

Em relação à dimensão organizacional, as PCDs consideram que predominam táticas individuais, informais, aleatórias e variáveis de integração, não havendo procedimentos de acompanhamento sistematizado e consideram que as organizações levam em conta o investimento anterior realizado por elas, em relação ao desenvolvimento de suas habilidades e aptidões. Com relação às condições 
de trabalho, as PCDs discordam muito ou totalmente que tenham sido realizadas adaptações das condições e instrumentos de trabalho visando à acessibilidade delas. Por outro lado, concordam que as organizações realizam atividades de sensibilização com vistas a facilitar o processo de socialização das PCDs; e discordam ou têm dúvida se houve adaptações das práticas de Recursos Humanos visando à inserção de PCDs. Com relação à dimensão organizacional, uma fala é bastante representativa do contexto analisado: "A empresa busca uma boa adequação, mas até o momento nada foi feito de fato. Acredito que para ambos os lados é uma experiência nova e que ainda não houve acerto".

Em relação aos fatores que podem contribuir para que as pessoas se mantenham nas organizações, indicam a importância do trabalho na vida delas, tanto do ponto de vista da sobrevivência e autonomia financeira como da possibilidade de reconhecimento social e profissional: "Foi a necessidade financeira, interesse financeiro"; "A principio foi necessidade mesmo, não financeira em si, porque nunca vivi sem. O que mudou foi mesmo o emocional, o trabalho dignifica o ser humano. Sem trabalho, fico sem lugar, sem nada a contribuir. Oportunidade única, eu não podia perder, fui bem sucedida, tô feliz". Esses resultados ratificam estudos anteriores que indicam a importância do trabalho para as PCDs, por exemplo, Martins (1996); Carvalho-Freitas, Marques e Scherer (2005), dentre outros.

Ressaltam também a segurança, autonomia e o bom relacionamento com os colegas: "Eu me sinto segura no que eu faço hoje"; "Fiquei mais seguro por ir me acostumando com o trabalho". Essa constatação indica as mudanças que vão ocorrendo ao longo do processo de socialização e que contribuem para uma melhor integração das PCDs.

Por último, é necessário considerar as projeções de futuro profissional das PCDs, tendo sido possível constatar que a maioria dos respondentes pretende fazer graduação, o que demonstra preocupação com a qualificação. Por outro lado, é possível considerar ainda que muitos dos entrevistados pretendem progredir na carreira, o que não se restringe unicamente à organização na qual trabalham: "Se não for aqui dentro, será em outro lugar, vou tentar outro concurso", "Aqui, é o princípio de muitas oportunidades que virão"; "Pretendo crescer dentro da organização, caso eu tenha que sair, estou pronta para o mercado de trabalho".

\section{Segunda etapa da pesquisa}

Visando a verificar, em uma amostra maior, se havia relações entre as táticas de socialização privilegiadas pelas
PCDs em seus processos de socialização e a percepção que tinham das adequações das condições e práticas de trabalho realizadas nas organizações em que trabalhavam, foram entrevistadas 33 PCDs de quatro instituições financeiras.

Com base nos dados da pesquisa, é possível observar que a maioria das PCDs inseridas em instituições financeiras privadas na Região Metropolitana de Belo Horizonte é do sexo feminino $(57,6 \%)$, solteira $(57,6 \%)$, com idade predominante entre 25 e 29 anos (41,9\%). No tocante à cor, observa-se que a maioria da amostra se declarou branca $(57,6 \%)$, e ressalta-se que nenhum entrevistado se declarou negro. A maioria dos sujeitos possui elevado nível de escolaridade, havendo um total de $69,7 \%$ com nível de escolaridade correspondente ao superior incompleto e completo. A respeito do tipo de deficiência que os sujeitos entrevistados possuem, notou-se somente a presença das deficiências auditiva e física, sendo esta última encontrada na maioria dos sujeitos $(87,9 \%)$. As demais deficiências (visual, múltipla) não foram apresentadas por nenhum entrevistado.

Considerando os aspectos funcionais da amostra pesquisada, observa-se que a maioria já havia trabalhado no mercado informal anteriormente $(51,5 \%)$, mas que o atual emprego não se apresenta enquanto primeiro emprego formal $(90,9 \%)$. A maior parte dos entrevistados já teve dois empregos formais anteriormente $(39,4 \%)$, com um tempo total de permanência neles entre 1 e 5 anos (45,5\%). Em relação ao atual emprego, observa-se que a maioria o conseguiu por meio do Sistema de Cotas $(73,3 \%)$, com permanência de 1 a 5 anos (45,5\%). Eles ocupam, em sua maioria, cargo de nível operacional/administrativo (70\%); no entanto, $30 \%$ exercem funções gerenciais (gerentes ou subgerentes) e possuem nível salarial equivalente a três salários mínimos $(54,5 \%)$.

\section{Táticas de socialização utilizadas no trabalho}

Em relação às táticas de socialização adotadas pelas PCDs, especialmente sobre o processo de busca de informações, domínios que abrangem o processo de socialização (Ostroff e Kozlowski, 1992), verificou-se que: em relação ao domínio do trabalho propriamente dito, $87,9 \%$ das PCDs buscam ativamente informações sobre o modo de fazer o trabalho, principalmente com colegas, superiores e por meio de informativos internos das organizações. Em relação à aprendizagem do papel social do cargo dentro da organização, 75,8\% das pessoas buscam informações sobre as expectativas da organização em relação ao trabalho delas, principalmente com seus chefes imediatos. Sobre as informações sobre o grupo de trabalho, $84,9 \%$ 
das pessoas têm observado e conversado com as pessoas buscando conhecer e se integrar ao grupo de trabalho. Sobre os valores e atributos organizacionais, $85 \%$ das pessoas têm buscado informações sobre a organização em que trabalha, principalmente com o superior imediato, colegas, intranet e internet.

Em relação a esses domínios de informações, verificouse que as pessoas privilegiam todos eles (trabalho propriamente dito, papel social, processos de grupo e valores organizacionais). Interessante notar que a estratégia adotada, na maioria das vezes, é a busca de informações com outras pessoas, sendo as principais fontes de informações as chefias imediatas e os colegas. Essa constatação reafirma a importância das chefias e colegas de trabalho no processo de socialização das PCDs e seu papel nos processos de inserção dessas pessoas no mundo do trabalho.

Em relação às táticas que as PCDs têm utilizado para se integrar nas organizações, pode-se constatar que elas utilizam várias delas: 81,3\% buscam informações; $69,7 \%$ procuram saber como o trabalho delas tem sido avaliado: $90,9 \%$ busca manter um bom relacionamento com as pessoas; $84,8 \%$ buscam ajuda junto aos colegas de trabalho e junto à chefia imediata; $42,5 \%$ negociam mudanças nas atividades de trabalho se têm dificuldades para realizá-las; $84,9 \%$ buscam estar atentos às informações divulgadas na organização, envolver-se nas atividades relacionadas ao seu trabalho, observar seu ambiente de trabalho, definir formas de se desenvolver e fazer carreira na organização; e 63,7\% fazem regularmente autoavaliação de seu desempenho. Outras táticas foram enumeradas por elas: manter bom relacionamento, atender bem aos clientes, bater as metas estipuladas, envolver-se nos projetos da empresa e participar de cursos, treinamentos em serviços, etc.

\section{Fatores relacionados às condições de trabalho}

Foram analisados os três fatores relacionados à percepção das condições e prática de trabalho:

Sensibilização - Sobre as informações que recebem quanto à saúde e segurança no trabalho, a maioria da amostra concorda que essas informações são oferecidas de forma acessível (79\%). Observou-se que 60\% das PCDs entrevistadas relataram que são realizadas atividades de formação, instrução e informação para o seu benefício. Além disso, $82 \%$ delas relataram que essas informações são veiculadas de forma a não colocá-las em desvantagem em relação às demais pessoas que não possuem deficiência. Concordam ainda que é realizada a sensibilização das chefias (82\%) e grupos de trabalho com relação à inserção de PCDs (82\%).

Adaptações - A respeito das adaptações físicas necessárias à inserção dessas pessoas (rampas, elevadores, de- graus sinalizados com cores vivas, adaptação de banheiros e bebedouros etc.), $79 \%$ dos respondentes afirmaram que elas foram realizadas no local de trabalho. Com relação às aquisições ou modificações dos locais de trabalho que visem à locomoção e ao acesso das PCDs, $82 \%$ da amostra afirmaram que elas têm ocorrido. E $70 \%$ dos sujeitos afirmaram que há redistribuição de tarefas conforme as suas necessidades, e que é feita alocação das PCDs em áreas de fácil acesso (76\%).

Práticas de RH - Pouco mais de metade da amostra $(51,5 \%)$ afirmou que há treinamento das Brigadas de Incêndio para a evacuação de PCDs. A maioria dos sujeitos afirmou que os procedimentos de promoção e transferência das PCDs são sistematizados, tendo por critério a capacidade (85\%) e experiência no trabalho (88\%). Além disso, 67\% dos entrevistados afirmaram que durante o processo de seleção os procedimentos utilizados asseguraram a possibilidade de realização por parte deles.

Analisando as possíveis relações entre as táticas de socialização e as condições de trabalho percebidas pelas PCDs, verifica-se que:

1. Quanto maior a percepção de que são realizadas atividades de sensibilização, mais as PCDs buscam ativamente informações sobre o modo de fazer o trabalho (domínio do trabalho, $r=0,444$, nível significância < 0,01 ); mais essas pessoas buscam informações sobre as expectativas da organização em relação ao trabalho delas (papel social, $r=0,368$, nível significância $<0,05$ ); além disso, mais elas utilizam as seguintes estratégias para se integrar na organização: buscam se relacionar com as pessoas $(r=0,434$, nível significância $<0,05)$; buscam ajuda junto aos colegas de trabalho $(r=0,376$, nível significância $<0,05)$; e buscam definir formas de se desenvolver e fazer carreira na organização $(r=$ 0,367, nível significância $<0,05$ ).

2. Quanto maior a percepção de que existem adaptações das condições de trabalho, mais as PCDs buscam ativamente informações sobre o modo de fazer o trabalho (domínio do trabalho, $r=0,437$, nível significância < $0,05)$; mais essas pessoas buscam informações sobre as expectativas da organização em relação ao trabalho delas (papel social, $r=0,423$, nível significância $<0,05$ ); além disso, mais elas utilizam as seguintes estratégias para se integrar na organização: buscam se relacionar com as pessoas $(r=0,525$, nível significância $<0,01)$; buscam ajuda junto aos colegas de trabalho $(r=0,354$, nível significância $<0,05$ ); e buscam fazer regularmente uma autoavaliação de seu desempenho $(r=0,362$, nível significância < 0,05). 
3. Quanto mais elas percebem a adequação de práticas de RH, mais elas utilizam as seguintes estratégias para se integrar na organização: buscam informações $(r=0,429$, nível significância $<0,05)$; buscam saber como o trabalho é avaliado $(r=0,466$, nível significância $<0,01$ ); ficam atentas às informações divulgadas na organização $(r=0,416$, nível significância < 0,05); buscam fazer regularmente uma autoavaliação de seu desempenho $(r=0,396$, nível significância $<0,05$ ); e buscam definir formas de se desenvolver e fazer carreira na organização $(r=0,490$, nível significância $<0,01)$.

\section{CONSIDERAÇÕES FINAIS}

A investigação apresentada possibilitou a identificação de táticas individualizadas desenvolvidas pelas PCDs no processo de socialização, com predominância de comportamentos mais proativos, visando a assegurar a manutenção de seus empregos, resultados esses similares aos de pesquisa realizada com pessoas que não possuem deficiência (GRIFFIN, COLELLA e GOPARAJU, 2000).

No entanto, é importante sublinhar que, ao deixar a socialização das PCDs mais dependente de suas ações particulares, pode-se criar um processo de paralisação dessas pessoas, principalmente se nunca tiveram experiências anteriores de trabalho. Pesquisas anteriores indicam que, quando as táticas de socialização são institucionalizadas, elas propiciam menor ambiguidade, conflito de papéis e intenção de deixar o emprego, além de menor ansiedade (COOPER-TOMAS e ANDERSON, 2006).

Uma contribuição específica dessa pesquisa foi analisar as associações entre as táticas individualizadas utilizadas e a percepção de ações de adequação das práticas e condições de trabalho para a inserção de PCDs, tendo verificado que as PCDs assumem comportamentos mais proativos quando percebem que essas ações de adequação ocorrem nas organizações. Por outro lado, a pesquisa reafirma a importância das chefias e colegas de trabalho no processo de socialização das PCDs, como já identificado em pesquisas anteriores como a de Gates (1993).

Esses resultados denotam a necessidade de introduzir, nas organizações, políticas efetivas de diversidade que se desdobrem em normas e procedimentos práticos de: seleção, tendo por critério as potencialidades das PCDs e a flexibilidade da organização em fazer as adaptações necessárias para efetivamente trabalhar com as diferenças; sensibilização das chefias e colegas de trabalho; e estratégias institucionalizadas de socialização, por meio de expo- sição efetiva e formalizada dessas pessoas aos valores da organização por meio de treinamentos, acompanhamentos ou tutoria, além de serem informados sobre a expectativa em relação ao trabalho que irão desenvolver, aos resultados, possibilidades de crescimento etc, e sobre a abertura para negociação a respeito das condições e instrumentos de trabalho que não as coloquem em desvantagem em relação aos demais colaboradores.

Finalizando, ressaltam-se os limites desta pesquisa, que trabalhou com amostras de conveniência, sendo necessárias novas pesquisas sobre o processo de socialização de PCDs em outras regiões do país. Entretanto, ela permitiu identificar experiências de inserção de PCDs no trabalho que podem servir como referência para comparação com outras organizações.

\section{NOTA DA REDAÇÃO}

Artigo originalmente apresentado no EnANPAD 2009 e submetido à RAE em regime de fast-track.

\section{REFERÊNCIAS}

AGÊNCIA EUROPEIA PARA A SEGURANÇA E A SAÚDE NO TRABALHO Garantir a segurança e a saúde dos trabalhadores com deficiência. Facts, ed. 53. Disponível em: http://agency.osha.eu.int/publications/factsheets/53/ pt/index.htm. Acesso em 24.01.2005.

BAHIA, M. S. Responsabilidade social e diversidade nas organizações: contratando PCDs. Rio de Janeiro: Qualitymark, 2006.

BARDIN, L. Análise de conteúdo. Lisboa: Edições 70, 1994

BARKER, W. K. Allen and Meyer's 1990 longitudinal study: a reanalysis and reinterpretation using structural equation modeling. Human Relations, v. 48, n. 3, p. 169-189, 1995.

BATISTA, C. A. M. Inclusão: construção na diversidade. Belo Horizonte: Armazém de Ideias, 2004.

BORGES, L. O; ALBUQUERQUE, F. J. B. Socialização Organizacional. In ZANELLI, J. C. e outros. (Orgs) Psicologia, organizações e trabalho no Brasil. Porto Alegre: Artmed, 2004. p. 331-356.

BRASIL. Decreto n. 3.298, de 20 de dezembro de 1999. Regulamenta a Lei n. 7.853 , de 24 de outubro de 1989, que dispõe sobre a Política Nacional para a Integração da Pessoa Portadora de Deficiência, consolida as normas de proteção, e dá outras providências. 
BRASIL. Lei n. 8.213, de 24 de julho de 1991. Dispõe sobre os Planos de Benefícios da Previdência Social e dá outras providências.

CARVALHO-FREITAS, M. N. Ações de adequação das condições e práticas de trabalho para a inserção de PCDs. Psicología para América Latina, v. 16, art. 9, 2009.

CARVALHO-FREITAS, M. N. A Inserção de PCDs em empresas brasileiras. Um estudo sobre as relações entre concepções de deficiência, condições de trabalho e qualidade de vida no trabalho. 2007. 314 f. Tese de Doutorado em Administração da Faculdade de Ciências Econômicas, Centro de PósGraduação e Pesquisas em Administração, Universidade Federal de Minas Gerais, Belo Horizonte, 2007.

CARVALHO-FREITAS, M. N. Organização escolar e socialização profissional de professores iniciantes. Cadernos de Pesquisa, n. 115, p. 155-172, 2002.

CARVALHO-FREITAS, M. N; MARQUES, A. L; SCHERER, F. L. Inclusão no mercado de trabalho: um estudo com pessoas portadoras de deficiência. RPA Brasil, v. 1, n. 1, p. 57-66, 2005.

CARVALHO-FREITAS, M. N; NEPOMUCENO, M. F; MARQUES, A. L. Suposições básicas sobre a natureza do comportamento humano e sobre o trabalho de PCDs. In: ENCONTRO ANUAL DA ASSOCIAÇÃO NACIONAL DOS PROGRAMAS DE PÓS-GRADUAÇÃO EM ADMINISTRAÇÃO, 32, 2008, Rio de Janeiro. Anais Eletrônicos. Rio de Janeiro: ANPAD, 2008. 1 CD-ROM.

CARVALHO-FREITAS, M. N; MARQUES, A. L. Trabalho e pessoas com deficiência: pesquisas, práticas e instrumentos de diagnóstico. Curitiba: Juruá, 2008.

COLELLA, A. The organizational socialization of employees with disabilities: theory and research. In: FERRIS, G. R. (Org) Research in personnel and human resources management. Greenwich, CT: JAI Press, 1996.

CONFERENCIA INTERNACIONAL DEL TRABAJO. La discriminación basada en la discapacidad 158. División de Población: World Population Prospects: The 2004 Revision, Base de datos de población, en la dirección. Conferência Internacional del Trabajo, Reunión 96, 2007.

COOPER-THOMAS, H. D.; ANDERSON, N. Organizational socialization: a new theoretical model and recommendations for future research and HRM practices in organizations. Journal of Managerial Psychology, v. 21, n. 5, p. 492-516, 2006.

CROCHÍK, J. L. Preconceito, indivíduo e sociedade. Temas em Psicologia, n. 3, p. 47-70, 1996.

DUBAR, C. A socialização: construção das identidades sociais e profissionais. Porto, Portugal: Porto Editora, 1997.

FREUND, P. Bodies, disability and spaces: the social model and disabling spatial organisations. Disability \& Society, v. 16, n. 5, p. 689-706, 2001.
GATES, L. B. The role of supervisor in successful adjustment to work with a disabling condition: issues for disability policy and practice. Journal of Occupational Rehabilitation, v. 3, n. 3, p. 179-194, 1993.

GLAT, R. Integração dos portadores de deficiências: uma questão psicossocial. Temas em Psicologia, Ribeirão Preto, v. 3, n. 2, p. 89-94, 1995

GOFFMAN, E. Estigma: notas sobre a manipulação da identidade deteriorada. 4. ed. São Paulo: J. Zahar, 1982.

GOSS, D; GOSS, F; ADAM-SMITH, D. Disability and employment: a comparative critique of UK legislation. The International Journal of Human Resource Management, v. 11, n. 4, p. 807-821, 2000.

GRIFFin, A. E. C; COlella, A; GOPARAJU, S. Newcomer and organizational socialization tactics: an interactionist perspective. Human Resource Management Review, v. 10, n. 4, p. 453-474, 2000.

HEINSKI, R. M. M. S; BIGNETTI, L. P. A inclusão de pessoas portadoras de deficiência no mercado de trabalho. In: Conselho Latinoamericano de Escolas de Administração, 2002, Porto Alegre. Anais Eletrônicos. Porto Alegre: CLADEA, 2002. 1CD-ROM.

HITT, M. A; MILLER, C. C; COLELLA, A. Comportamento organizacional: uma abordagem estratégica. Rio de Janeiro: LTC, 2007.

INSTITUTO BRASILEIRO DE GEOGRAFIA E ESTATÍSTICA. Censo 2000 Sistema IBGE de Recuperação Automática - SIDRA, 2002 Disponível em: http//www.sidra.ibge.gov.br. Acesso em 08.09.2009.

JONES, G. R. Socialization tactics, self-efficacy, and newcomers' adjustments to organizations. Academy of Management Journal, v. 29, n. 2, p. 262-279, 1986.

KITCHIN, R. 'Out of place', 'Knowing one's place': space, power and the exclusion of disabled people. Disability \& Society, v. 13, n. 3, p. 343356,1998

LEWIS, G. B; ALLEE, C. L. The impact of disabilities on federal career success. Public Administration Review, v. 53, n. 4, p. 389-397, 1992.

LIMA, M. Como empregar sem discriminar. Ciência e Profissão - Diálogos, n. 5 , p. 19-21, 2007

MARQUES, C. A construção do anormal: uma estratégia de poder In. ENCONTRO ANUAL DA ASSOCIAÇÃO NACIONAL DE PÓSGRADUAÇÃO EM EDUCAÇÃO, 24, 2001, Caxambu. Anais Eletrônicos. Caxambu: ANPED, 2001. 1 CD-ROM.

MARQUES, C. A. A estetização do espaço: perspectivas de inserção ou de exclusão da pessoa portadora de deficiência. Temas sobre desenvolvimento, v. 8, n. 47 , p. 10-16, 1999

MARTINS, S. M. F. C. Deficiência física e mercado de trabalho: o ponto de vista do trabalhador deficiente. Consciência, v. 10, n. 1, p. 55-70, 1996. 


\section{MARIA NIVALDA DE CARVALHO-FREITAS - ISADORA D'ÁVILA TOLEDO - MARISTELA FERRO NEPOMUCENO • JANAYNA DE CÁSSIA COELHO SUZANO • LUCIANA ALVES DRUMOND ALMEIDA}

MILLER, V. D; JABLIN, F. M. Information seeking during organizational entry: influences, tactics, and a model of the process. Academy of Management Review, v. 16, n. 1, p. 92-120, 1991.

NERI, M. e outros. Retratos da deficiência no Brasil. Rio de Janeiro: FGV/ IBRE, CPS, 2003.

NOHARA, J. J; ACEVEDO, C. R; FIAMMETTI, M. A vida no trabalho: as representações sociais das pessoas com deficiência. In: CARVALHOFREITAS, M. N; MARQUES, A. L. Trabalho e pessoas com deficiência: pesquisas, práticas e instrumentos de diagnóstico. Curitiba: Juruá, 2008.

OLIVEIRA, M. H. A. Núcleos cooperativos: uma perspectiva profissional para o portador de deficiência. Em Aberto, Brasília, ano 13, n. 60, p. 106108, 1993

OMOTE, S. Estereótipos a respeito de pessoas deficientes. Didática, v. 22, n. $22 / 23$, p. $167-180,1987$

ORGANIZAČ̃̃O INTERNACIONAL DO TRABALHO. Disability and work. http://www.ilo.org/public/english/employment/skills/disability/index.htm. Acesso em 20.04.2009.

OSTROFF, C; KOZLOWSKI, S. J. Organizational socialization as a learning process: the role of information acquisition. Personnel Psychology, v. 45, n. 4, p. 849-874, 1992.

POPOVICH, P. M. e outros. The assessment of attitudes toward individuals with disabilities in the workplace. The Journal of Psychology, v. 137, n. 2, p. 163-177, 2003

QUINTÃO, D. T. R. Algumas reflexões sobre a pessoa portadora de deficiência e sua relação com o social. Psicologia \& Sociedade, v. 17, n. 1, p. 17-28, 2005.
RIBEIRO, M. A; RIBEIRO, F. Gestão organizacional da diversidade: um estudo de caso de um programa de inclusão de pessoas com deficiência. In: CARVALHO-FREITAS, M. N; MARQUES, A. L. Trabalho e pessoas com deficiência: pesquisas, práticas e instrumentos de diagnóstico. Curitiba: Juruá, 2008. p. 122-141.

SAKS, A. M; ASHFORTH, B. E. Organizational socialization: making sense of past and present as a prologue for the future. Journal of Vocational Behavior, v. 51, n.2, p. 234-279, 1997.

SECRETARIA INTERNACIONAL DO TRABALHO. Gestão de questões relativas à deficiência no local de trabalho: Repertório de recomendações práticas da OIT. Tradução de Edilson Alkmin Cunha; revisão técnica de João Baptista Cintra Ribas. 1. ed. rev. Brasília: OIT, 2006.

SIQUEIRA, M. V. S; OLIVEIRA-SIMÕES, J. T. Violência moral e pessoas com deficiência: constrangimentos e humilhações no ambiente de trabalho. In: CARVALHO-FREITAS, M. N; MARQUES, A. L. Trabalho e pessoas com deficiência: pesquisas, práticas e instrumentos de diagnóstico. Curitiba: Juruá, 2008. p. 187-199.

STONE, D. L; COLELLA, A. A model of factors affecting the treatment of disabled individuals in organizations. Academy of Management Review, $\mathrm{v}$ 21. n. 2, 1996. 28 p.

TANAKA, E. D. O; MANZINI, J. E. O que os empregadores pensam sobre o trabalho da pessoa com deficiência? Revista Brasileira de Educação Especial, v. 11, n. 2, p. 273-294, 2005.

VAN MAANEN, J; SCHEIN, E. H. Toward a theory of organizational socialization. Research in Organizational Behavior, v. 1, n. 1, p. 209264,1979

VIVARTA, V. (Coord) Mídia e deficiência. Brasília: Andi; Fundação Banco do Brasil, 2003 